\title{
Журбенко В.А. \\ Современные представления о профилактике воспалительных заболеваний пародонта
}

ФГБОУ ВО Курский Государственный Медицинский Университет Мин-здрава России

doi: $10.18411 / \mathrm{j}-02-2021-28$

(Россия, Курск)

idsp: ljournal-02-2021-28

\section{Аннотация}

Заболевания пародонта являются одной из актуальных проблем стоматологии. Это связано, прежде всего, с высокими показателями распространенности, а также значительными изменениями в зубочелюстной системе, наблюдаемые при данной патологии. Развитию патологических процессов в пародонте могут способствовать различные причины, как местные, так и общие. В связи с этим особый научный и практический интерес представляют вопросы профилактики, так как заболевания пародонта наблюдаются практически во всех возрастных группах населения. В обзорной статье приведены основные направления профилактики заболеваний пародонта.

Ключевые слова: Заболевания пародонта, профилактика, общегосударственные меры, индивидуальная профилактика, возрастные периоды.

\section{Abstract}

Periodontal diseases are one of the most pressing problems of dentistry. This is primarily due to the high prevalence rates, as well as significant changes in the dentoalveolar system observed in this pathology. Various causes, both local and general, can contribute to the development of pathological processes in the periodontium. In this regard, prevention issues are of particular scientific and practical interest, since periodontal diseases are observed in almost all age groups of the population. The review article presents the main directions of prevention of periodontal diseases.

Keywords: Periodontal diseases, prevention, national measures, individual prevention, age periods.

Проблема профилактики болезней пародонта занимает одно из ведущих мест в современной стоматологии. Важность этой проблемы определяется широкой распространенностью заболеваний пародонта во всем мире, тяжестью их течения, негативным влиянием на здоровье человека [1]. По данным ВО3, каждый взрослый человек старше 30 лет страдает заболеваниями пародонта в той или иной степени. Так, в общей структуре оказания медицинской помощи больным в лечебнопрофилактических учреждениях стоматологического профиля заболевания пародонта составляют до $90 \%$ от общего числа обращений и встречаются у лиц разного возраста [2]. Резкое увеличение распространенности заболеваний пародонта, потеря большого количества зубов в результате их прогрессирования, что, в свою очередь, обусловливает возникновение вторичных деформаций зубных рядов и патологии височно-нижнечелюстного сустава, нарушение акта жевания и речи, влияние на общее состояние организма и снижение качества жизни человека требуют пристального внимания специалистов к данной патологии не только как к общемедицинской, но и социальной проблеме.

Профилактика - комплекс государственных, медицинских, социальных, гигиенических мер, направленных на сохранение здоровья пациента и предупреждения заболевания ротовой полости [2]. 
Целью профилактики является устранение причин, которые могут повлечь за собой заболевание; сохранение здоровья пациента без радикальных вмешательств и с наиболее щадящими процедурами; повышение устойчивости организма к вредным факторам.

Комплекс первичных профилактических мер предусматривает:

1) гигиеническое воспитание населения (обучение уходу за полостью рта);

2) реализацию программы рационального питания;

3) регулярное посещение врача-стоматолога для проведения лечебно профилактических вмешательств, которое сводится к контролю за гигиеническим состоянием ротовой полости, снятию зубных отложений, рациональному ортодонтическому и ортопедическому лечению при аномалиях и дефектах зубных рядов.

Основной целью вторичной профилактики является лечение ранних признаков патологических изменений в тканях пародонта с целью предупреждения их прогрессирования.

Составными компонентами вторичной профилактики являются:

1) полноценный гигиенический уход за полостью рта пациента, демонстрация правильной чистки зубов, проведение контрольных чисток зубов с использованием индикаторных веществ;

2) исключение травматических факторов;

3) аппликация фторсодержащих и реминерализующих средств для предупреждения развития кариеса;

4) рентгенологический контроль, повторяемый не ранее, чем через год, что позволяет выявить характер и интенсивность деструктивных процессов в костной ткани альвеолярных отростков;

5) хирургическое устранение факторов, способствующих развитию патологических изменений в пародонте (углубление преддверия полости рта, устранение рубцовых деформаций слизистой оболочки переходной складки, перемещение высоко прикрепленной уздечки нижней губы и низко прикрепленной уздечки верхней губы).

Третичная профилактика включает весь комплекс терапевтических, хирургических, ортодонтических и ортопедических мероприятий, направленных на купирование патологического процесса, предупреждение осложнений и восстановление функции жевательного аппарата.

Приведенная схема профилактических мер свидетельствует о том, что основу предупреждения заболеваний пародонта составляют первичный и вторичный комплексы, т.е. профилактические, а не лечебные мероприятия [3].

Из множества мер профилактики можно выделить две основные группы: общегосударственные и индивидуальные, которые включают мероприятия, осуществляемые с участием врача и самим пациентом.

Основными компонентами общегосударственных мер профилактики заболеваний пародонта являются:

1) обязательная санация детей и подростков;

2) диспансерные осмотры;

3) санация беременных женщин.

К числу мер индивидуальной профилактики, осуществляемых врачом стоматологом относятся:

1) регулярное снятие зубных отложений,

2) лечение гингивита,

3) вмешательства ортопедического и ортодонтического, хирургического характера,

4) физиотерапевтические процедуры. 
Самостоятельно пациентом осуществляется уход за полостью рта, аутомассаж десен, полоскание полости рта и рациональное питание - с конкретными рекомендациями врача. Что же касается гигиенического ухода за полостью рта, то обучение правилам чистки зубов относится одновременно и к общегосударственным и индивидуальным мероприятиям, выполняемым с участием врача и самостоятельно самим пациентом. Гигиеническое воспитание (или обучение) необходимо проводить в самых широких масштабах во всех организованных коллективах - детских, учебных или производственных. Но даже при высоком уровне санитарно-просветительной работы в процессе регулярно повторяемых осмотров врачу необходимо напоминать пациентам о правилах ухода за полостью рта, демонстрировать технику чистки зубов и проводить непосредственно в кабинете контрольную чистку с использованием индикаторных средств [4].

Таким образом, изложенные мероприятия составляют основу профилактических комплексов. Эффективность профилактических средств и методов определяется тем, насколько в ходе их применения удается устранить причинный фактор или сделать невозможным его влияние.

Структурно-функциональные особенности тканей пародонта в различных возрастных периодах человека дают основание для рекомендации и специфических мер профилактики на каждом из них.

Выделяют также схему профилактики заболеваний пародонта, предложенную акад. А. И. Рыбаковым с учетом возрастных периодов жизни человека.

I. Внутриутробный период.

1. Рациональный режим беременности. Выявление генетического фона.

2. Рациональное сбалансированное питание беременных женщин: белки животного и растительного происхождения не менее 1,5-2,0 г/кг; углеводы: ограничение легкоусвояемых углеводов до 6 г/кг; жиры (насыщенные и ненасыщенные) 1,5 г/кг; минеральные компоненты: кальций - 0,5 г/сут., фосфор - 1,5-2,0г/сут., фтор из расчета содержания в воде 1 мг/л.

3. Максимальное ограничение медикаментов.

II. $\quad$ 0-6 лет - период формирования пародонта временных зубов.

1. Рациональный общий режим матери и ребенка - преимущественно естественное вскармливание. При искусственном - обеспечение достаточного поступления питательных веществ и солей в организме ребенка из расчета на 1 кг массы ребенка: белков; жиров; углеводов.

2. Профилактика воспалительных изменений в пародонте и слизистой оболочке полости рта.

3. Устранение деформаций уздечки и аномалий слизистой оболочки преддверия рта.

4. Тренировка жевательного аппарата ребенка с целью обеспечения условий для нормального формирования временного прикуса (борьба с вредными привычками, твердая пища, сырые овощи и фрукты, профилактика деформаций зубных рядов ребенка посредством профилактики кариеса временных зубов при помощи регулярного покрытия их фторсодержащим лаком, регулярной санации полости рта).

5. Ранние ортодонтические и ортопедические вмешательства при наличии дефектов зубных рядов и деформаций челюстей.

6. Максимальное исключение антибиотиков тетрациклинового ряда и сульфаниламидов.

7. Выявление иммунодефицитных состояний ребенка.

8. Прививание гигиенических навыков с 2-х-летнего возраста. 

прикуса.

III. 6-20 лет - период развития и формирования пародонта постоянного

1. Рациональный режим жизни и питания ребенка в школе и дома;

a) полное исключение сладостей между приемами пищи;

б) достаточное поступление кальция (1,5 г/сут.); фосфора (2,5 г/сут.), аминокислот и фосфатидов (с включением в пищу нерафинированных растительных масел в количестве $10 \%$ от общего количества жиров);

в) обеспечение достаточной нагрузки на жевательный аппарат (сырые овощи, фрукты, уменьшение продуктов после тонкой кулинарной обработки).

2. Коррекция деформации верхнего отдела скелета детей при помощи ортодонтической аппаратуры и специальных гимнастических комплексов.

3. Полноценный комплекс лечебных мероприятий у детей с врожденной патологией зубов и пародонта.

4. Выявление и своевременное лечение детей с гингивитом, диспансерное наблюдение за детьми.

5. Регулярная санация полости рта и ЛОР-органов. Широкое использование фторлаков и реминерализующих растворов при профилактике кариеса зубов.

6. Максимальное исключение антибиотиков, стероидов и прочих сильнодействующих медикаментозных средств.

7. Тренировка общей сосудистой системы и сосудов пародонта чередованием температурных факторов, с использованием массирующих процедур приротовой области.

8. Устранение местных факторов развития заболеваний пародонта (пришлифовывание преждевременно контактирующих бугров, при показаниях ортопедические и ортодонтические вмешательства, устранение дефектов структуры слизистой оболочки полости рта состояние уздечек, преддверия полости рта).

9. Использование гигиенических средств, предупреждающих развитие патологических процессов в пародонте.

IV. $\quad$ 20-40 лет - период активной функции зубочелюстного аппарата.

1. Рациональный общий режим и режим питания:

a) интенсивная физическая нагрузка на организм;

б) сбалансированное питание;

в) увеличение потребления продуктов: молочных, морских, овощей.

К мероприятиям, рекомендованным в III возрастном периоде добавляются такие, как устранение или нейтрализация действия профессиональных вредных агентов на ткани пародонта, комплекс мероприятий, предупреждающих развитие склеротических изменений в сосудах пародонта, использование курортных факторов и др.

В V возрастном периоде (40 лет и старше) профилактические мероприятия практически идентичны, как и в IV возрастной группе. Однако большее внимание уделяется режиму питания в соответствии с возрастом, профилактике развития соматической патологии и стрессовых ситуаций, устранению гипоксии организма и тканей пародонта.

Обязательным компонентом профилактики является диспансеризация населения. Диспансеризация пародонтологических больных - активный метод сохранения здоровья населения, направленный на выявление ранних форм заболевания и факторов риска, включающих комплекс лечебно-профилактических, социально гигиенических мероприятий, позволяющих сохранить функции зубочелюстной системы. 
Последовательное и регулярное проведение перечисленных мероприятий с учетом возрастных особенностей развития организма и в частности, тканей пародонта является важным фактором, способным обеспечить эффективность профилактики заболеваний пародонта.

$$
* * *
$$

1. Грудянов А.И., Овчинникова В.В. Профилактика воспалительных заболеваний пародонта. - М.: ООО "Медицинское информационное агентство", 2007. - 80 с.

2. Кузьмина Э.М., Кузьмина И.Н., Петрина Е.С. и др. Стоматологическая заболеваемость населения России. Состояние тканей пародонта и слизистой оболочки полости рта. М.: МГМСУ, 2009. 228.

3. Журбенко, В.А. Профилактические мероприятия для предупреждения заболевания тканей пародонта / В.А. Журбенко, А.А. Мурашова // В сборнике: Наука и практика в XXI веке. Межвузовский сборник научных трудов с международным участием. Составитель Е.В. Метельская. - Астрахань. - 2019. - С. 192-195.

4. Журбенко, В.А. Индивидуальная профилактика заболеваний пародонта / В.А. Журбенко, Э.С. Саакян // Международный журнал прикладных и фундаментальных исследований. - 2017. - № 4-3. - C. 616.

5. Журбенко, В.А. Гигиена полости рта как метод профилактики заболе-ваний пародонта / В.А. Журбенко, Э.С. Саакян // Актуальные проблемы и до-стижения в медицине. Сборник научных трудов по итогам международной научно - практической конференции. - № 2. - Самара. - 2015. C. $152-154$

\title{
Мингалева А.А., Семелева Е.В., Смирнова О.А. Клинико-психологические аспекты здоровьесбережения среди пациентов хирургического профиля
}

\author{
ФГБОУ ВО МГУ им. Н.П. Огарева \\ (Россия, Саранск)
}

doi: $10.18411 / \mathrm{j}-02-2021-29$

idsp: ljournal-02-2021-29

\section{Аннотация}

Снижение медицинской активности населения зачастую связано с длительностью лечения и необходимостью выполнения дополнительных инвазивных и физиотерапевтических процедур. Несоблюдение рекомендаций по лечению или частичное их выполнение зачастую приводит к неполному выздоровлению, хронизации заболевания и его прогрессированию (осложнению), что приводит к неизбежности хирургического вмешательства.

Ключевые слова: медицинская активность, хирургическое лечение, здоровье, медицинская помощь.

\section{Abstract}

A decrease in the medical activity of the population is often associated with the duration of treatment and the need to perform additional invasive and physiotherapeutic procedures. Failure to comply with treatment recommendations or their partial implementation often leads to incomplete recovery, chronicity of the disease and its progression (complication), which leads to the inevitability of surgical intervention.

Key words: medical activity, surgical treatment, health, medical care.

При проведении хирургических мероприятий психологическая готовность пациентов является важным компонентом лечебно-реабилитационного процесса, от которого напрямую зависит успех лечения.

Все варианты поведенческих реакций хирургических больных в значительной степени зависят от способа адаптации пациента к заболеванию и от сформированной им внутренней картины болезни. Исход лечения хирургических больных 